\title{
Indigenous Knowledge, Practices, Beliefs and Social Impacts of Porcine Cysticercosis and Epilepsy in Iringa Rural
}

\author{
Mwita Chacha*, Coletha Yohana, Gamba Nkwengulila \\ Department of Zoology and Wildlife Conservation, University of Dar es Salaam, Dar es Salaam, Tanzania \\ Email: mwitachacha@udsm.ac.tz
}

Received 17 September 2014; revised 2 November 2014; accepted 17 November 2014

Copyright (C) 2014 by authors and Scientific Research Publishing Inc.

This work is licensed under the Creative Commons Attribution International License (CC BY). http://creativecommons.org/licenses/by/4.0/

\section{(c) (7) Open Access}

\section{Abstract}

Porcine Cysticercosis (PCC) and Human Cysticercosis (HCC)/Neurocysticercosis (NCC) are a burden to the community owing to the reduced value of animals, associated costs of treatment, decreased labour productivity and social discrimination. There is limited knowledge on the management and prevention of PCC and epilepsy in Iringa rural. Therefore, the present study aimed at assessing indigenous knowledge, practices, attitudes and social impacts of PCC and epilepsy in Iringa rural district. A total of 588 people participated in the survey whereby 306 were pig farmers, 223 non-pig farmers and 59 families with epileptic individuals. It was found that $49.8 \%\left(\chi^{2}=\right.$ $0.003, \mathrm{DF}=1, \mathrm{p}=0.954$ ) of pig keepers were aware of PCC, whereas the remaining $50.2 \%$ were not aware $\left(\chi^{2}=25.5, \mathrm{DF}=1, \mathrm{p}<0.001\right)$. The prevalence of late onset epilepsy was significantly higher $(62.7 \%)$ than that of those who manifested seizures and convulsions in childhood $37.3 \%\left(\chi^{2}=\right.$ 3.814, $\mathrm{DF}=1, \mathrm{p}=0.51$ ). People in Iringa rural believe epilepsy is caused by evil spirits, witchcraft and/or inheritance. It was concluded that there was limited knowledge on $T$. solium cysticercosis and epilepsy. This ignorance is the cause of poor practices, negative beliefs and attitudes that negatively affect the social life of People with Epilepsy (PWE) in communities. This study recommends that health education to raise awareness on cysticercosis/taeniosis and epilepsy should be one of the intervention measures for elimination of cysticercosis and epilepsy in Iringa rural district.

\section{Keywords}

Neurocysticercosis, Knowledge, Beliefs, Practices, Stigmatization, Segregation

\footnotetext{
${ }^{*}$ Corresponding author.
} 


\section{Introduction}

Taenia solium cysticercosis and the associated public health and economic consequences are a growing problem in poor areas of Africa, Asia and Latin America where people eat pork and keep pigs in traditional ways [1]-[3]. The disease is emerging as an important threat to public health and economic well-being of resource-poor smallholder farming communities [4] [5]. The epidemiology of porcine and human cysticercosis is associated with unhygienic habits and free range pig keeping [6] [7]. Effective control of Taenia solium therefore, requires knowledge on the life cycle, patterns of infection and the associated risk factors [8] [9].

Consequently, the lack of knowledge on the epidemiology of porcine and human cysticercosis leads to practices that encourage the transmission and persistence of Taenia solium [10] [11]. For instance, traditional healers are believed to use a mixture of tapeworm segments and other medicine to treat severe intestinal tapeworm infections [12]. Similarly, it is reported that some women use the contents of tapeworm segments as punishment to their unfaithful husbands or lovers [12] [13]. Elsewhere in developed countries, however, knowledge on T. solium cysticercosis is substantial and thus porcine and human cysticercosis is not a big problem as it is in developing countries [14] [15]. Therefore, prevalence of PCC and HCC in Eastern and Southern Africa (ESA) ranks among the highest in the world [16].

Neurocysticercosis (NCC) refers to infection of the brain by the larval form of the pork tapeworm T. solium. It is a form of HCC and the main causes of late onset epilepsy. Epilepsy is a devastating clinical problem in communities where there is little education, high rates of poverty, and poor access to health care [17]. Furthermore, the ignorance on the causes of epilepsy and its impacts has resulted into misunderstandings in communities [18]-[20]. The disease is thus emerging as an important social constraint in developing countries particularly in rural communities due to stigmatization and discrimination [21]. People suffering from epilepsy are often misunderstood, ostracised, and limited in their participation in society [17]. It is also considered as contagious, resulting in rejection and even isolation of affected individuals [22]. In some rural communities epileptic seizures are perceived as punishment for sins, a curse and bewitchment or demonic possession [20]. The family members experience shame and may choose to keep the person suffering from epilepsy confined to the home [17]. The segregation and discrimination of epileptic people develop inferiority complex which affects their quality of life [19]. Eradication of epilepsy due to T. solium parasite requires the disruption of its life cycle [13]. Likewise, the elimination of discrimination and segregation to people with epilepsy requires proper knowledge on the management which will be able to remove inferiority complex. Therefore, the present study found it necessary to assess the indigenous knowledge, practices and social impacts related to PCC and epilepsy in Iringa rural district.

\section{Materials and Methods}

\subsection{Study Site}

The study was carried out in the following villages: Kising'a, Igingilianyi, Ihominyi, Mikongw'i, Matembo, Ilambilole, Kihorogota, Igula, Ngano, Kiwere, Mfyome, Kipera, Nyamihuu, Nyang’oro, Chamdindi, Holo, Ikengeze, Mangawe, Malengamakali, Nyakavangala, Mkulula, Usolanga, Iguluba, Makadupa, Kibena, Muwimbi, Ifunda, Mibikimitali, Mfukulembe, Udumuka, Migoli and Mtera. These villages were selected from nine wards of Iringa rural district, Tanzania as per illustration in Figure 1. The district lies at $1600-2700 \mathrm{~m}$ above sea level, with an area of 20,576 sq. kms, and an estimated population of 245,625 people. Average temperatures are normally below $15^{\circ} \mathrm{C}$ with rainfall ranging between $1000 \mathrm{~mm}$ to $1600 \mathrm{~mm}$ per annum falling in a single season from November to May. The dry and cold season occurs after the rain season and lasts from June to September.

\subsection{Methods}

\subsubsection{Study Design and Population Surveyed}

The survey was carried out in the selected wards from July 2012 to August 2012. The households with pigs were randomly selected to participate in the study. The infection in pigs was inspected by lingual palpation and confirmed through postmortem examination. The questionnaire and interviews were used to collect data on risk factors for taeniosis, which was verified via direct observation. 


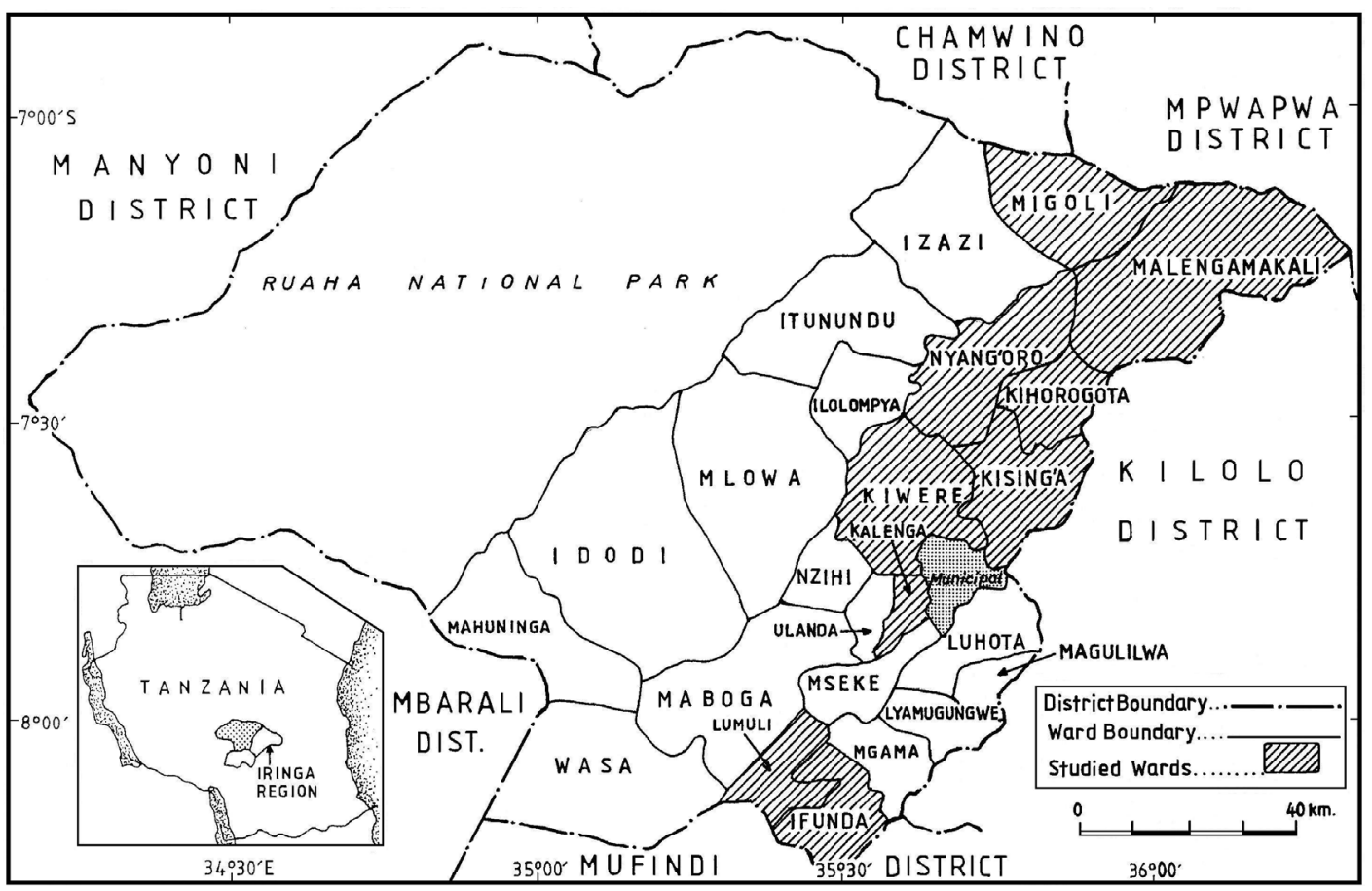

Figure 1. Iringa rural district, study sites.

\subsubsection{Sample Size Estimation}

The sample size estimation was calculated using the formula: $n=Z^{2} P Q / L^{2}$ [23] where: $n$ is the number of pigs, $Z$ is the score for a given confidence interval, $P$ is a known estimated prevalence whereby for the present study was $8.4 \%$ the prevalence reported by Boa et al. [24], $Q=(1-P)$ and $L$ is the permissible error of estimation. In this study the desired confidence interval was $95 \%$ with the permissible error of an estimation of $0.05 \%$. Therefore, based on the formula the sample size was calculated as $n=1.96^{2} \times 0.084 \times 0.916 / 0.05^{2}=118$. In order to maximize the number of respondents, the sample size 118 was then multiplied by 1.5 or $150 / 100 * 118=177$. Using simple random sampling a total of 588 participants were involved whereby 306 were pig farmers, 223 non-pig farmers and 59 families with epileptic individuals.

\subsubsection{Data Collection}

\section{1) Questionnaire administered to pig keepers.}

The structured questionnaire had a range of questions including: time since started to raise pigs, ways of keeping pigs, awareness of PCC, transmission of $T$. solium cysticercosis to pigs, ways of prevention, the fate of affected pigs, clandestine (non-official) market, preference of eating pork, pork preparation methods, place of finding pork, hygienic and sanitary practices, how human acquire tapeworms.

\section{2) Questionnaire administered to families with epileptic individuals and non-pig keepers.}

The structured questionnaire comprised of a range of questions including; the age of epileptic individual; time since the epileptic signs manifested; symptoms; place of treatment, reasons for selecting type of treatment, awareness on the causes of epilepsy, means of transmission, means of prevention, knowing somebody with epilepsy, effects of epilepsy, segregation and discrimination to individuals and family members in marriage and reasons for segregation.

\subsubsection{Data Analysis}

Data on indigenous knowledge, practices and beliefs were analyzed by the statistical package for social sciences version 19.0 for windows (SPSS Inc., Chicago, IL, USA). The significance of parametric data was tested using t-test and non-parametric data were tested by using Chi-square analysis. P-value less or equal to 0.05 was considered to be significant. The $95 \%$ confidence interval was used in the present study (CI $=95 \%)$ for various factors at individual level. 


\section{Results}

\subsection{Community Knowledge and Practices on Porcine Cysticercosis}

A total of 306 pig keepers were surveyed during the study for the assessment of knowledge and practices on $T$. solium cysticercosis. About $49.8 \%\left(\chi^{2}=0.003, \mathrm{DF}=1, \mathrm{p}=0.954\right)$ of the pig farmers were aware of PCC, but among these only $33.7 \%$ knew that human faeces were the source of $T$. solium cysticercosis infection to pigs. About $50.2 \%(n=306)$ believed that cysticercosis in pigs was caused by jiggers and mice. Thirty five percent (35\%) of non-pig keepers were aware of pork tapeworms and $21.7 \%$ believed pork and vegetables or unwashed fruits as the source of taeniasis in humans. About $44.8 \%$ of the respondents mentioned "under the tongue" as the predilection site for cysts in pigs, 8.5\% mentioned "under the skin and legs" and 46.8\% did not know. Only $31.8 \%$ of pig keepers were able to detect (identify) cysts in live pigs. The general community's awareness on the pork tapeworm was high (59.1\%) but knowledge on transmission was low $(35.0 \%)\left(\chi^{2}=25.5\right.$, DF $=1$, p $<$ 0.001 ). About $22.7 \%$ slaughtered pigs at home and sold uninspected pork. The majority of the surveyed population $89.8 \%\left(\chi^{2}=185.287, \mathrm{DF}=1, \mathrm{p}<0.001\right)$ eat pork; while $10.2 \%$ do not eat pork due to various reasons including allergy and religious beliefs (Table 1 ).

\subsection{Community Knowledge, Practice, Belief and Social Impacts on Epilepsy}

A total of 282 participants responded to the questionnaire on the assessment of knowledge, practices and beliefs on epilepsy. About 54.7\% $(n=276)$ of respondents knew somebody with epilepsy, but the majority were ignorant on the prevention measures for the epileptic condition $65.6 \%,\left(\chi^{2}=41.362\right.$, DF $\left.=1, \mathrm{p}<0.05\right)$. In Iringa rural $62.7 \%$ of the epileptic individuals had late onset (adulthood) epilepsy, whereas 37.3\% developed seizure since childhood. When an individual showed epileptic symptoms, the hospital was the preferred place for treatment (56.9\%), (30.4\%) used traditional healer and 12.7\% used both hospitals and traditional healing. The choice of treatment was mostly determined by family decision $(80.8 \%)\left(\chi^{2}=88.615\right.$, DF $\left.=1, \mathrm{p}=0.001\right)$ and the beliefs of the sufferer were slightly considered (19.2\%).

Based on the responses of the surveyed population in Iringa rural, epilepsy is caused by different agents. About (38.2\%) sited evil spirits and/or witchcraft as causes of epilepsy, 24\% sited pork and other raw/undercooked foods, $18 \%$ sited personal hygiene and $20.1 \%$ said it was inherited from parents. Over half (56.6\%) of respondents believed epilepsy was transmitted from one person to another by sleeping with an epileptic individual, and 8.5\% mentioned sex and contact with the saliva of epileptic patients during convulsions.

Epilepsy was reported by respondents to have various consequences on the health of the sufferers; physical discomfort was the most (67.5\%) pronounced effect; other effects included falling (16.8\%) and failure to work (15.7\%). About 69.5\% of epileptic people experienced headaches. In school children poor performance was the most sited (44.7\%) effect, and being forced to drop from school was the least sited (15.4\%) effect. About 73.7\% of respondents considered epileptic individuals as disabled who needed close attention, while $65.3 \%$ reported that epileptic individuals were not allowed in community gatherings because of unpredictable attacks manifested by seizures, convulsions and personal discomfort. About 67.4\% $(n=261)$ responded that family members did not segregate epileptic individuals but the segregation and discrimination arises during social functions. Both people with epilepsy (51.5\%) and $48.5 \%$ of the other members of the family experience difficulties in getting married. In marriage, epilepsy was the source of quarrels (58.7\%), and at sometimes caused divorce (12.2\%) (Table 2).

\section{Discussion}

Indigenous knowledge (IK) is a set of perceptions, information and behaviours that guide members of particular community towards a certain way of living or behaving. It can be used in various sectors for instance in veterinary medicine with the intimate understanding of their environments [25]. In the present study jiggers and mice were mentioned as the causes of Porcine Cysticercosis (PCC). The incrimination of jiggers as the causative agents for PCC might be due to their similarity in morphology to T. solium cysts. Furthermore, the mention of "legs" and "under the skin" as the predilection of T. solium cysticercosis in pigs was due to morphological misconception between jiggers and T. solium cysts.

Some pig farmers know that indiscriminate disposal of human faeces is central to the transmission of $T$. solium infection. Most of such farmers live along the main roads and were frequently visited by paravets. On the 
Table 1. Community knowledge and practices on porcine cysticercosis.

\begin{tabular}{|c|c|}
\hline Factors & Responses (\%) \\
\hline Knowledge on $T$. solium cysticercus $(n=299)$ & 49.8 \\
\hline Yes & 50.2 \\
\hline \multicolumn{2}{|l|}{ No } \\
\hline \multicolumn{2}{|l|}{ Possibility to see cysticercus in live pigs $(n=277)$} \\
\hline Yes & 31.8 \\
\hline No & 68.2 \\
\hline \multicolumn{2}{|l|}{ Predilection sites for cysts in live pigs $(\mathrm{n}=\mathbf{2 0 1})$} \\
\hline Under skin & 8.5 \\
\hline Under the tongue & 44.8 \\
\hline Don’t know & 46.8 \\
\hline \multicolumn{2}{|l|}{ How human can get tapeworm $(n=198)$} \\
\hline Through pork & 59.1 \\
\hline Without washing hands & 5.6 \\
\hline Contaminated food and water & 16.2 \\
\hline Don’t know & 9.2 \\
\hline \multicolumn{2}{|l|}{ Do you know anything about tapeworm $(n=283)$} \\
\hline Yes & 35 \\
\hline No & 65 \\
\hline \multicolumn{2}{|c|}{ How pigs can be infected by $T$. solium cysticercosis $(n=288)$} \\
\hline Human feaces & 33.7 \\
\hline Pigs feaces & 4.9 \\
\hline From pigs with larva & 12.8 \\
\hline Don’t know & 48.7 \\
\hline \multicolumn{2}{|c|}{ What do you do when your pig is infected with cysticercus $(n=260)$} \\
\hline Selling pigs & 3.8 \\
\hline Giving the local medicine & 12.3 \\
\hline Destroying the larva & 8.1 \\
\hline Don’t know & 47.3 \\
\hline Other means & 28.5 \\
\hline \multicolumn{2}{|c|}{ Which methods are used to prevent cysticercosis infection in pigs $(n=280)$} \\
\hline Using pigpen & 36.4 \\
\hline Local medicine & 3.6 \\
\hline Cleaning the environment & 30.4 \\
\hline Don’t know & 29.6 \\
\hline \multicolumn{2}{|c|}{ Have you ever diagnosed cysts in your pigs $(n=285)$} \\
\hline Yes & 20.7 \\
\hline No & 79.3 \\
\hline \multicolumn{2}{|l|}{ Did you manage to sell your infected pigs $(n=59)$} \\
\hline Yes & 35.1 \\
\hline No & 64.9 \\
\hline \multicolumn{2}{|c|}{ Do you prefer to slaughter pigs at your home $(n=295)$} \\
\hline Yes & 22.7 \\
\hline No & 77.3 \\
\hline
\end{tabular}




\section{Continued}

Do you prefer eating pork $(n=293)$

Yes

No

What type of preparation do you prefer most $(n=284)$

Fried

Boiled

Roasted

Where do you get pork $(n=274)$

From known butcher

From local clubs

From people house

Table 2. Community knowledge, practice, belief and social impacts of epilepsy.

When did you start to suffer $(n=59)$

Childhood

Late onset

Sudden falling $(n=173)$

Yes

No

Health consequences of epilepsy $(n=203)$

Falling and convulsion

Physical discomfort

Functional impairment

Do you experience headache $(n=59)$

Yes

No

The place epileptic patients seek treatment $(n=220)$

Hospitals

Traditional healer

Both

The reasons for the choice of a place for treatment $(n=277)$

Family affordability of treatment cost

Belief of the sick person

Knowledge on causes of epilepsy $(n=267)$

Evil spirits

Food related

Personal hygiene

Inheritance from parents

Knowledge on ways to prevent epilepsy $(n=294)$

Yes 


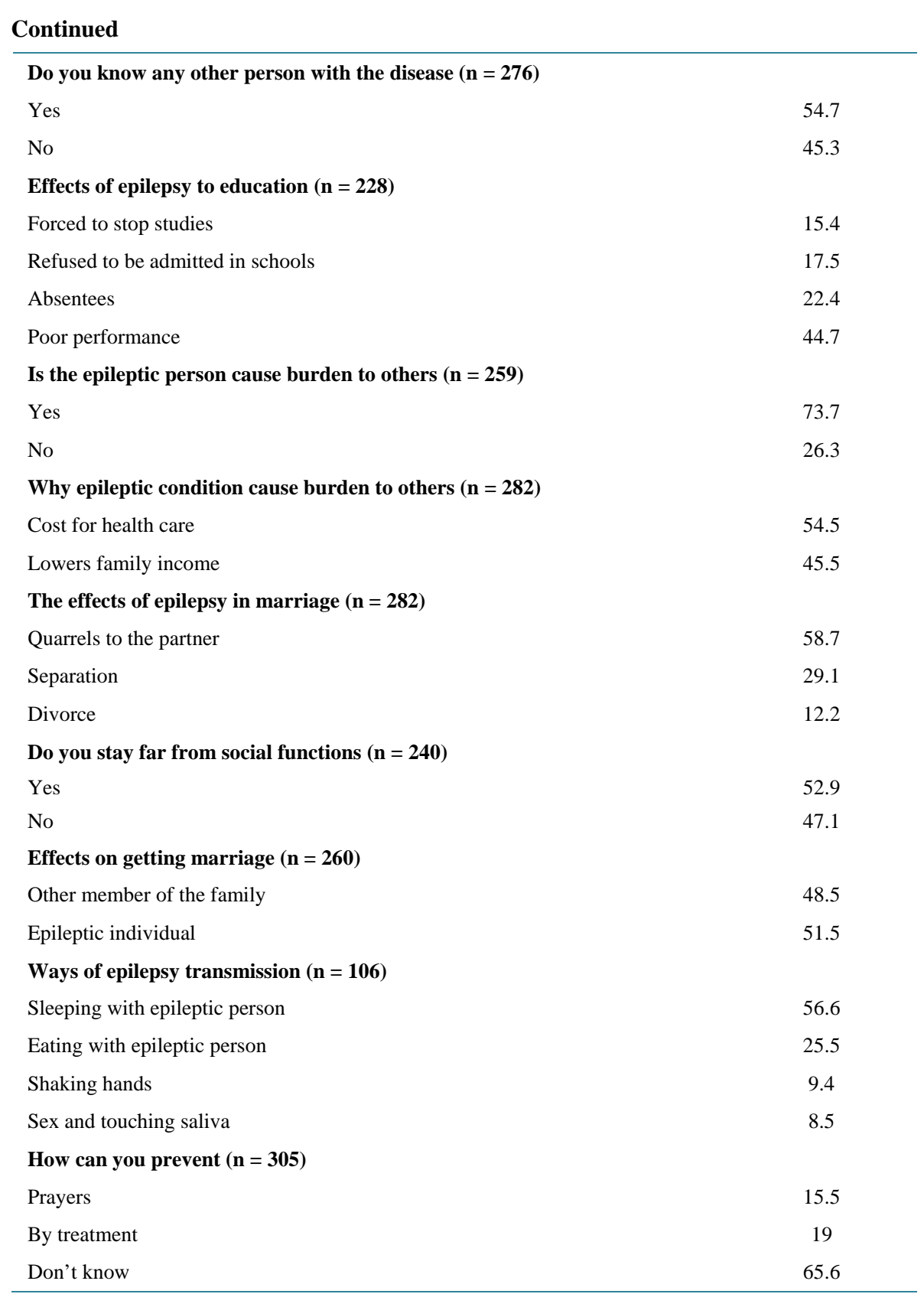

other hand, non-pig producers had little understanding of the pork tapeworm (T. solium) and how it is transmitted, because such knowledge was provided by paravets through livestock seminars. The lingual muscle was the best site for ante-mortem diagnosis of cysticerci infection in pigs and was understood by most pig farmers in Iringa rural. Unfortunately, the method requires physical force and technique, this is probably the reason most pig farmers failed to diagnose the infection in pigs.

Despite that paravets provided knowledge on PCC and other animal diseases through livestock seminars, they only focused on livestock problems and did not link with human health. Additionally, while paravets insisted on indoor pig keeping, they did not include packages on the elimination of diseases. This might explain the fact that neither pig farmers nor non-pig farmers had knowledge on the prevention of cysticercosis infection in pigs and humans in the study area. Likewise, the health workers in dispensaries and health centers provided education on environmental sanitation, personal hygiene and related matters. Unfortunately, only the sick and expectant mothers attend such seminars while the large population remained uniformed. It is, therefore, justifiable to rec- 
ommend the scaling up of the efforts to educate people on the causes, transmission and prevention of the T. solium parasite in Iringa rural communities.

About $62.7 \%$ of epileptic people involved in the present study developed seizures from the age of 21 years onwards. Secka et al. [26] reported similar observations in Gambia, they noted that people aged between 21 - 40 were the most affected compared to other age categories but was not caused by cysticercosis. It could be surmised that most epileptic cases reported in the present study could be due to NCC (neurocysticercosis), though confirmation was beyond the scope of the present study. It was believed, in the studied areas that the late appearance of epileptic symptoms (particularly seizures) was associated with evil spirits and witchcraft, which promoted fears and negative perceptions towards epilepsy; childhood epilepsy was passed down from parents (inherited). In addition, evil spirits, witchcraft and food allergy were mentioned as causes of epilepsy, which corroborates the findings by Joseph et al. [27]. The association of evil spirits as the cause of epilepsy might be due to the reason that epilepsy is incurable; this leads people to believe that epilepsy could be cured through prayers and traditional healing.

Furthermore, the social discrimination of people with epilepsy was increased by the belief that epilepsy could be transmitted through contact (e.g. touching saliva, sleeping together and shaking hands). The sudden falling accompanied with convulsions created fear among families and friends not to allow epileptic individuals into large gatherings. The segregation and discrimination experienced by epileptic people induced in them an inferiority complex that was the cause of their failure to live with their partners in marriage. Likewise, the belief that epilepsy could be transmitted through sex and that it can be inherited leads to discrimination of epileptic people and the members of their families in marriage [28]. Therefore, it is necessary that knowledge on epilepsy is provided to communities for the elimination of the negative perceptions and attitudes for the betterment of the welfare of epileptic people.

Since, sudden falling and convulsions often lead into injury to epileptic individuals, care is therefore, needed to protect them as when it happens it renders them helpless. In school children, epilepsy often interrupts attendance and effective schooling, resulting into truancy, poor performances and sometimes withdrawal from school. Sanya et al. [19] reported that when children are recognized to be suffering from epilepsy they could be denied admission into some schools. Discrimination has serious psychological consequences to epileptic individuals; they often develop a sense of not being wanted, an inferiority complex that degrades the quality of their life. Generally the community does not understand the causes, transmission, prevention and how to manage epilepsy, particularly late onset epilepsy. The lack of knowledge on causes and prevention of epilepsy lead people proposing close care and providing balanced diet as the means of preventing epileptic person from acquiring other diseases. Therefore, it is necessary to educate people about late onset epilepsy so as to reduce the impacts that result from social segregation and discrimination.

\section{Conclusion}

There was little knowledge on the causes, transmission and prevention of $T$. solium cysticercosis and epilepsy in Iringa rural areas. The continued persistence of PCC in the study area is contributed by absence of meat inspection and hygiene, slaughter slabs and consumption of uninspected pork. The proportion of condemned pigs due to $T$. solium cysticercosis was negligible because the affected pigs were slaughtered at home and pork was sold in street bars and in the community. There were more cases of late onset epilepsy than those of childhood epilepsy. People have limited knowledge on the causes and transmission of epilepsy; this has led to social segregation and discrimination of epileptic individuals. Since both pig keepers and non-pig keepers have little knowledge on $T$. solium infection in humans, it is imperative to provide education on the life cycle of $T$. solium as part of the control efforts of the disease in Iringa rural areas.

\section{Limitations/Weakness}

- Financial: Consistency coverage of the proposed study areas could not be achieved due to financial constrains.

- Community consent: A few people simply refused to participate in the project and thus some good information was not disclosed.

- Information on socio-demographic characteristics of the participants was not documented and hence forms one of the weaknesses to this study. 


\section{Acknowledgements}

The authors acknowledge support from the consortium Afrique One "Ecosystem and Population Health: Expanding Frontiers in Health”. Afrique One is funded by the Wellcome Trust (WT087535MA).

\section{References}

[1] Gonzalez, A.E., Castro, M., Gilman, R.H., Vargas, G., Sterling, C.R., Garcia, H.H., Diaz, F., Miranda, E., Naranjo, J., Herrera, G., Carcamo, C., Verastegui, M., Montenegro, T., Alvarez, M., Torres, M.P., Tsang, V., Pilcher, J., Chavera, A., Delgado, A., Lozano, J., Henderson, P., Armas, F., Rodriguez, T., Evans, C., Vasquez, L.E. and Cama, V. (1993) The marketing of Cysticercotic Pigs in the Sierra of Peru. Bulletin of the World Health Organization, 71, 223-228.

[2] Engels, D. and Savioli, L. (2006) Reconsidering the Underestimated Burden Caused by Neglected Tropical Diseases. Trends in Parasitology, 22, 363-366. http://dx.doi.org/10.1016/j.pt.2006.06.004

[3] Hotez, P.J. (2009) The Neglected Tropical Diseases and Their Devastating Health and Economic Impact on the Member Nations of the Organisation of the Islamic Conference. PLoS Neglected Tropical Diseases, 5, e539. http://dx.doi.org/10.1371/journal.pntd.0000539

[4] Bern, C., Garcia, H.H., Evans, C., Gonzalez, A.E., Verastegui, M. and Tsang, V.C.W. (1996) Magnitude of the Disease Burden from Neurocysticercosis in a Developing Country. Current Infectious Diseases, 29, 1203-1209. http://dx.doi.org/10.1086/313470

[5] Waiswa, C., Fevre, E.M., Nsadha, Z., Sikasunge, C.S. and Willingham III, A.L. (2011) Porcine Cysticercosis in Southeast Uganda, Seroprevalence in Kamuli and Kaliro Districts. Journal of Parasitology Research, 9, 1-5.

[6] Sarti, E., Schantz, P.M., Lara-Aguilera, R., Gomez-Dantes, H. and Flisser, A. (1992) Epidemiological Observations on Porcine Cysticercosis in a Rural Community of Michoacan State Mexico. Veterinary Parasitology, 41, 195-201. http://dx.doi.org/10.1016/0304-4017(92)90079-O

[7] Perry, B.D. and Grace, D. (2009) The Impacts of Livestock Diseases and Their Control on Growth and Development Processes That Are Pro-Poor. Philosophical Transactions of the Royal Society, 364, 2643-2655. http://dx.doi.org/10.1098/rstb.2009.0097

[8] Ngowi, H.A., Carabin, H., Kassuku, A.A., Mlozi, M.R.S., Mlangwa, J.E.D. and Willingham III, A.L. (2008) HealthEducation Intervention Trial to Reduce Porcine Cysticercosis in Mbulu District Tanzania. Prevent Veterinary Medicine, 85, 52-67. http://dx.doi.org/10.1016/j.prevetmed.2007.12.014

[9] Kolaczinski, J.H., Hanson, K., Robinson, E., Picon, D. and Sabasio, A. (2010) Integrated Surveys of Neglected Tropical Diseases in Southern Sudan: How Much Do They Cost and Can They Be Refined? PLoS Neglected Tropical Disease, 4, e745. http://dx.doi.org/10.1371/journal.pntd.0000745

[10] Lescano, A.G., Garcia, R.H., Guezala, M.C., Tsang, V.C.W., Gavidia, M.C., Rodriguez, S., Moulton, L.H., Green, J.A., Gonzalez, E.A. and The Cysticercosis Working Group in Peru (2007) Swine Cysticercosis Hotspots Surrounding Taenia solium Tapeworm Carriers. American Journal of Tropical Medicine and Hygiene, 76, 376-383.

[11] Sorvillo, F.J., Patricia, W., Shira, S. and Mark, E. (2011) Public Health Implications of Cysticercosis Acquired in the United States. Emerging Infectious Disease, 17, 1-6. http://dx.doi.org/10.3201/eid1701.101210

[12] Ngowi, H.A., Phiri, I.K., Matenga, E., Afonso, S., Boa, M.E., Mutaratirwa, S., Githigia, S., Saimon, S.C., Maingi, N., Lubega, G.W., Kassuku, A., Michael, I., Siziya, S., Krecek, R.C., Noormahomed, E.V., Nsengiyumva, M., Andriantsimahavandy, A., Dorny, P., Johansen, M.V. and Willingham III, A.L. (2004) Taenia solium Cysticercosis in Eastern and Southern Africa: An Emerging Problem in Agriculture and Public Health. Journal of Tropical Medicine Public Health, 35, 266-270.

[13] Mafojane, N.A., Appleton, C.C., Krecek, R.C., Michael, L.M. and Willingham III, A.L. (2003) The Current Status of Neurocysticercosis in Eastern and Southern Africa. Acta Tropica, 87, 25-33. http://dx.doi.org/10.1016/S0001-706X(03)00052-4

[14] Jilek-Aall, L. and Rwiza, H.T. (1992) Prognosis of Epilepsy in a Rural African Community: A 30-Year Follow-Up of 164 Patients in an Outpatient Clinic in Rural Tanzania. Epilepsia, 33, 645-650.

http://dx.doi.org/10.1111/j.1528-1157.1992.tb02341.x

[15] Ngowi, H.A., Mlangwa, J.E.D., Mlozi, M.R.S., Tolma, E.L., Kassuku, A.A., Carabin, H. and Willingham III, A.L. (2009) Implementation and Evaluation of a Health-Promotion Strategy for Control of Taenia solium Infections in Northern Tanzania. International Journal of Health Promotion and Education, 47, 24-34. http://dx.doi.org/10.1080/14635240.2009.10708154

[16] Phiri, I.K., Ngowi, H., Afonso, S., Matenga, E., Boa, M., Mukaratirwa, S., Githigia, S., Saimo, M., Sikasunge, C., Maingi, N., Lubega, W.G., Kassuku, A., Michael, L., Siziya, S., Krecek, C.R., Noormahomed, E., Vilhena, M., Dorny, P. and Willingham III, A.L. (2003) The Emergence of Taenia solium Cysticercosis in Eastern and Southern Africa as a 
Serious Agricultural Problem and Public Health Risk. Acta Tropica, 87, 13-23.

[17] Cate, E.D., Florence, K.M., Mike, L. and Jared, M.W. (2011) Educating People Participating in the Pig Industry to Reduce Epilepsy Due to Taenia solium. Novel Aspects on Epilepsy, 12, 213-220.

[18] Marju, R., Andre, O. and Suley, H.K. (2000) Felt Stigma and Impact of Epilepsy on Employment Status among Estonian People: Exploratory Study. Seizure: European Journal of Epilepsy, 9, 394-401. http://dx.doi.org/10.1053/seiz.2000.0439

[19] Sanya, E.O., Salami, T.A.T., Goodman, O.O., Buhari, O.I.N. and Araoye, M.O. (2005) Perception and Attitude to Epilepsy among Teachers in Primary, Secondary and Tertiary Educational Institutions in Middle Belt Nigeria. Tropical Doctor, 35, 153-156. http://dx.doi.org/10.1258/0049475054620905

[20] Foyaca-Sibat, H., Del Rio-Romero, A. and Ibanez-Valdes, L. (2005) Prevalence of Epilepsy and General Knowledge about Neurocysticercosis at Ngangelizwe Location, South Africa. The International Journal of Neurology, 4.

[21] Alikor, E.A. and Essien, A.A. (2005) Childhood Epilepsy: Knowledge and Attitude of Primary School Teachers in Port Harcourt, Nigeria. Niger Journal of Medicine, 14, 299-303.

[22] Rwiza, H.T., Matuja, W.B.P., Kilonzo, G.P., Haule, J., Mbena, P., Mwangómbola, R., et al. (1993) Knowledge, Attitude, and Practice toward Epilepsy among Rural Tanzanian Residents. Epilepsia, 34, 1017-1023. http://dx.doi.org/10.1111/j.1528-1157.1993.tb02127.x

[23] Martin, S.W., Meek, A.H. and Willeberg, P. (1987) Veterinary Epidemiology, Principles and Methods. Iowa State University Press, Ames, 343.

[24] Boa, M.E., Mahundi, E.A., Kassuku, A.A., Willingham III, A.L. and Kyvsgaard, N.C. (2006) Epidemiological Survey of Swine Cysticercosis Using Ante-Mortem and Post-Mortem Examination Tests in the Southern Highlands of Tanzania. Veterinary Parasitology, 139, 249-255. http://dx.doi.org/10.1016/j.vetpar.2006.02.012

[25] Flavier, J.M., Navarro, C.S. and Warren, D.M. (1995) The Regional Program for the Promotion of Indigenous Knowledge in Asia. In: Warren, D.M., Slikkerveer, L.J. and Brokensha, D., Eds., The Cultural Dimension of Development: Indigenous Knowledge Systems, Intermediate Technology Publications, London, 479-487. http://dx.doi.org/10.3362/9781780444734.043

[26] Secka, A., Grimm, F., Victor, B., Marcotty, T., De Deken, R., Nyan, O., Herera, O., Van Marck, E. and Geerts, S. (2010) Epilepsy Is Not Caused by Cysticercosis in the Gambia. Tropical Medicine and International Health, 15, 476479.

[27] Joseph, I.S., Ricardo, A., Lopez, B., Blanca, V.C. and Peter, V.H.D. (2005) Qué es la Epilepsia? Attitudes and Knowledge of Epilepsy by Spanish-Speaking Adults in the United States. Epilepsy and Behavior, 7, 259-265. http://dx.doi.org/10.1016/j.yebeh.2005.04.015

[28] Preux, P.M., Thiemagni, F., Fodzo, L., Kandem, P., Ngouafong, P., Ndongo, F., Macharia, W., Dongmo, L. and Dumas, M. (2000) Antiepileptic Therapies in the Mifi Province in Cameroon. Epilepsia, 41, 432-439. http://dx.doi.org/10.1111/j.1528-1157.2000.tb00185.x 
Scientific Research Publishing (SCIRP) is one of the largest Open Access journal publishers. It is currently publishing more than 200 open access, online, peer-reviewed journals covering a wide range of academic disciplines. SCIRP serves the worldwide academic communities and contributes to the progress and application of science with its publication.

Other selected journals from SCIRP are listed as below. Submit your manuscript to us via either submit@scirp.org or Online Submission Portal.
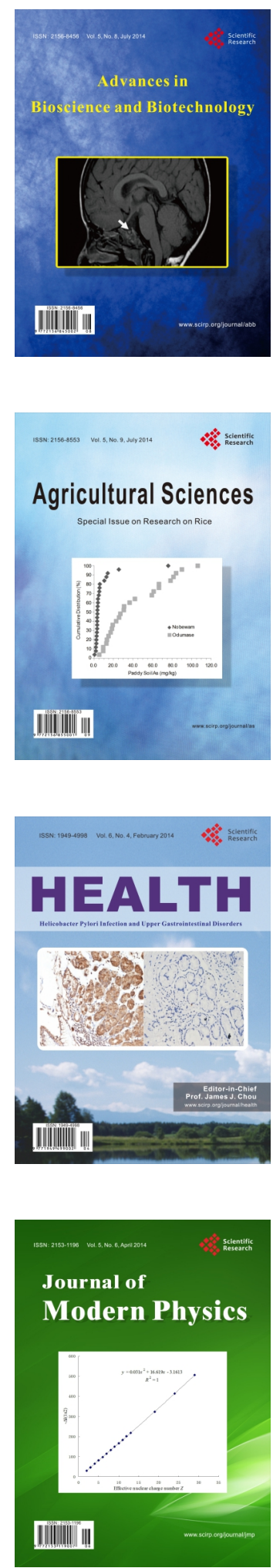
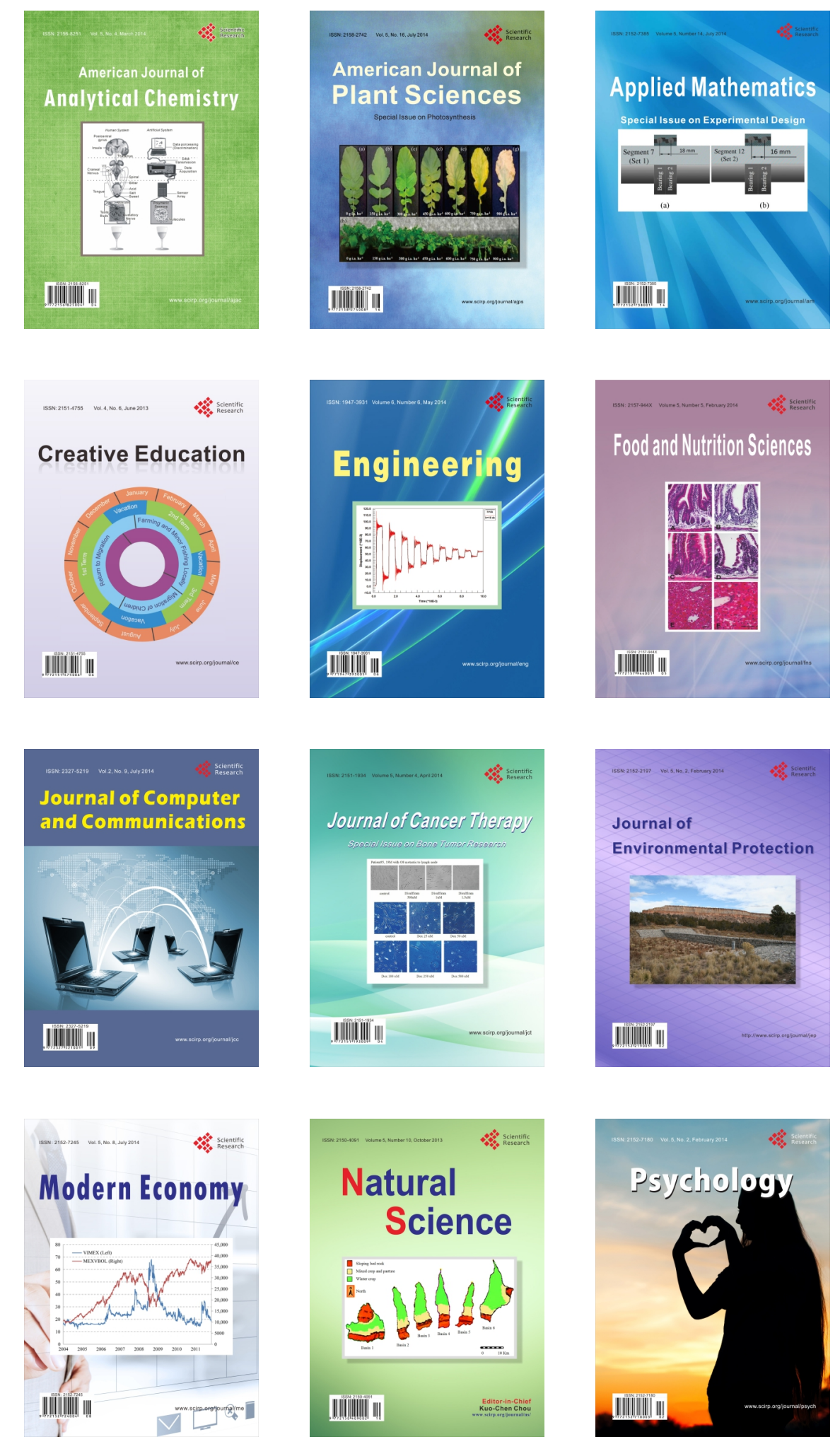